\title{
Antimicrobianos en COVID-19: parar ahora
}

\author{
Antimicrobials in COVID-19: stop now
}

Miguel Villegas-Chiroque ${ }^{1, a}$

La epidemia de la COVID-19 (enfermedad por el coronavirus 2019) se inició en Wuhan (Hubei, China) en diciembre del año pasado y fue producida por el SARS-CoV-2 (coronavirus tipo 2 del síndrome respiratorio agudo severo). Hasta la fecha se han registrado más de 50 millones de casos confirmados y cerca de 1,3 millones de fallecidos en todo el mundo, constituyendo la mayor pandemia ocurrida en el último siglo. Los países con mayor cantidad de casos son Estados Unidos (10,3 millones), India (8,6 millones) y Brazil (5,7 millones). Al momento, los países europeos se preparan para una inminente segunda ola, así Francia, y Rusia se acercan a los 2 millones de casos, mientras España, Reino Unido e Italia tienen más del millón de casos cada uno. En América Latina, conforme se aproxima el verano la pandemia parece alejarse, en concordancia con una supuesta estacionalidad de la COVID-19, no obstante, países como Argentina y Colombia también registran ya más del millón de casos de COVID-19 ${ }^{(1,2)}$.

En Perú, el Ministerio de Salud (MINSA) notifica 925 mil de casos y 35 mil fallecidos por la COVID-19, configurándose como uno de los países con mayor tasa de mortalidad en el mundo con el aproximado de mil decesos por millón de habitantes. No obstante, la cifra reportada por el Sistema Informático Nacional de Defunciones (SINADEF) del exceso de mortalidad señala más de 70 mil fallecidos este año, atribuidos a la pandemia de COVID-19 en el país, sin contar aún con los reportes manuales de certificados de defunción que representan el $30 \%$ del registro histórico en el país ${ }^{(3,4)}$. Estos datos son reflejo de la falta de liderazgo y políticas de Estado para afrontar la epidemia con el falso dilema de economía versus salud, sin prever el abastecimiento de oxígeno, pruebas moleculares, mascarillas, oxímetros de pulso y otros insumos a gran escala para hacer frente a la epidemia. Se sumó, la existencia de un sistema de salud fraccionado y desarticulado, y de la salud pública abandonado y obsoleto, sin priorizar el primer nivel de la atención.

El aprendizaje acerca de la enfermedad (COVID-19), el virus (SARS-CoV-2) y su transmisión es vasto; se reafirma lo que se conoce desde el principio: el virus se trasmite de persona a persona por contacto cercano a través de la vía respiratoria mediante gotitas de Flügge. La trasmisión por aerosoles es posible pero no común, ocurre en situaciones de hacinamiento y formación de conglomerados y en áreas hospitalarias donde se realiza procedimientos respiratorios. La trasmisión por contacto por fómites es más rara aún, debido a que el virus es sensible a la desecación, radiación ultravioleta y uso de solventes orgánicos (alcohol, lejía, detergentes). Sin embargo, su trasmisibilidad se favorece porque se trasmite desde infectados asintomáticos y sobretodo en presintomáticos, en un período de contagiosidad que va desde dos días antes del inicio de molestias hasta siete días después, teniendo un pico máximo al momento de aparición de los síntomas, por lo que la prevención en base a síntomas y pruebas de laboratorio tiene sus propias limitaciones $(5,6)$.

La COVID-19 es una enfermedad sistémica de trasmisión respiratoria, con período de incubación de cinco días en promedio (rango de 2 a 14 días), después empieza con fiebre, malestar general, congestión nasal, dolor faríngeo y/o diarreas (fase viral), los cuales remiten en días, pero luego reaparece la fiebre o se intensifica, hay tos seca, dolor torácico y dificultad respiratoria (fase neumónica) y en pocos casos continúa hasta un síndrome de distrés respiratorio del adulto (SDRA), falla multiorgánica, shock séptico y la muerte (fase hiperinflamatoria). Las imágenes muestran infiltrados periféricos bilaterales, a predominio basal, con patrón reticular en vidrio esmerilado. La analítica cursa con linfopenia y elevación de la PCR (proteína $\mathrm{C}$ reactiva). Su evolución y pronóstico depende de edad, género y comorbilidad: niños, jóvenes y mujeres no complican; mientras que, los varones de 45 o más años y adultos mayores con comorbilidad

\footnotetext{
1. Hospital Regional de Lambayeque. Chiclayo, Perú.

a. Doctor en Medicina. Médico infectólogo. Servicio de Infectología.

Orcid: https://orcid.org/0000-0002-8090-8224
} 
complican gravemente. Destaca ampliamente la obesidad y la diabetes, suponiendo algún factor genético relacionado con la cantidad de receptores virales ACE-2 y el estado proinflamatorio del paciente ${ }^{(7,8)}$.

El tratamiento es sintomático en casos leves a moderados, y de soporte en casos graves y críticos: hidratación adecuada, profilaxis de anticoagulación, oxigenoterapia con o sin ventilación mecánica y manejo de complicaciones. La terapia antiviral específica no ha tenido eficacia esperada de alguna molécula en la reducción de mortalidad, por lo que ahora hay una "nueva ola" de estudios para probar la eficacia de inmunomoduladores que actúen sobre el estado inflamatorio de la enfermedad, mientras se espera los resultados de eficacia y seguridad de las diversas vacunas en curso ${ }^{(6)}$. El uso de dexametasona a dosis bajas $(6 \mathrm{mg} /$ día por 10 días) ha demostrado reducción de la mortalidad en un tercio de pacientes con ventilación mecánica y un quinto de aquellos con solo necesidad de oxigenoterapia en el estudio Recovery del Reino Unido (9); sin embargo, a pesar de la advertencia de la OMS, el uso masivo de corticoides en diferentes dosis y esquemas terapéuticos ha sido la pauta del quehacer médico, desconcertados por no contar con armas efectivas.

El uso rutinario de antimicrobianos se instaló bajo la premisa de tratar las complicaciones bacterianas en la COVID-19, semejante a lo que ocurre con la influenza. No obstante, dos metanalisis revelan que la coinfección bacteriana en COVID-19 ocurre solo entre 3,5\% y $7 \%$ de los casos. Asimismo, la sobreinfección bacteriana se desarrolla solo en el $4 \%$ de hospitalización en salas mixtas y $14 \%$ en unidades de cuidados intensivos (UCI) ${ }^{(10,11)}$. Por ello, la recuperación de patógenos es poco común y el diagnóstico de infección bacteriana agregada se basa en la evolución clínica y laboratorial. Los reactantes de fase aguda no ayudan: la leucopenia inicial da paso a la leucocitosis inducida por corticoides, la PCR y la ferritina se encuentran elevados por la COVID-19. En cambio, la procalcitonina no se eleva en la COVID-19 leve o moderada, constituyendo el marcador más fiable en predecir infección bacteriana agregada o enfermedad crítica ${ }^{(12-14)}$.

Adicionalmente, se trata de justificar el "uso preventivo" de antimicrobianos debido a la inmunosupresión generada por el uso casi universal de corticoides sistémicos.

Los antimicrobianos de amplio espectro usados en forma indiscriminada y de corticoides sistémicos en pacientes con COVID-19 no graves son condiciones habituales para la selección de bacterias hospitalarias resistentes. Si se adiciona la aplicación inadecuada de medidas de bioseguridad como el uso innecesario y permanente de guantes y mandilones adicionales ("cultura del plástico") y la reducción drástica del lavado de manos por la aplicación obsesi- va de alcohol en gel, incluso sobre los guantes, entonces, se ofrecen condiciones favorables para las sobreinfecciones bacterianas multirresistentes. En el Hospital Regional Lambayeque enfrentamos un brote hospitalario por Acinetobacter baumanii complex multirresistente (datos no publicados), con potenciales consecuencias negativas sobre la morbimortalidad de pacientes, estancia y coste hospitalario. Por ello, son necesarias las acciones de los Programas de Optimización de uso de Antimicrobianos (PROA), los cuales deben ser fortalecidos institucionalmente para su desarrollo competente.

Finalmente, señalar que la epidemia de COVID-19 vino para quedarse entre nosotros y poco a poco se vuelve endémica, y mientras se desarrolla vacunas efectivas y aún con ellas debemos seguir lidiando con este mal, por lo que urge ya replantear las estrategias de manejo, entre las cuales queda obvio parar ahora el uso rutinario de antimicrobianos en pacientes con COVID-19 y cambiar de paradigma porque no aporta beneficio sino daño potencial a los pacientes y a las instituciones de salud.

Financiamiento: Autofinanciado.

Conflicto de interés: El autor declara que no existe conflicto de interés.

\section{REFERENCIAS BIBLIOGRÁFICAS}

1. Villegas-Chiroque M. Pandemia de COVID-19: pelea o huye: COVID-19. Rev Exp Med [Internet]. 5 de marzo de 2020 [citado 5 de agosto de 2020]; 6(1).Disponible en: http://rem.hrlamb.gob.pe/index.php/REM/ article/view/424

2. The Center for Systems Science and Engeeniering at Johns Hopkins University. Coronavirus COVID-2019 Global cases by Johns Hopkins CSSE. [internet]. Baltimore: CCSE JHU; 2020. [Citado el 11 de noviembre de 2020]. Disponible en: https://gisanddata.maps.arcgis.com/apps/ opsdashboard/index.html\#/bda7594740fd40299423467b48e9ecf6

3. Ministerio de Salud de Perú. Sala situacional COVID-19. [internet]. Lima: MINSA, 2020 [citado el 11 de noviembre de 2020]. Disponible en: https://covid19.minsa.gob.pe/sala_situacional.asp

4. Ministerio de Salud de Perú. Sistema Informático de Defunciones SINADEF. [internet]. Lima: MINSA, 2020 [citado el 11 de noviembre de 2020]. Disponible en: https://www.minsa.gob.pe/reunis/data/defunciones_registradas.asp

5. Cevik M, Kuppalli K, Kindrachuk J, Peiris M. Virology, transmission, and pathogenesis of SARS-CoV-2. BMJ. 2020 Oct 23;371:m3862. doi: 10.1136/bmj.m3862. PMID: 33097561.

6. Pascarella G, Strumia A, Piliego C, Bruno F, Del Buono R, Costa F, Scarlata S, Agrò FE. COVID-19 diagnosis and management: a comprehensive review. J Intern Med. 2020 Aug;288(2):192-206. doi: 10.1111/joim.13091. Epub 2020 May 13. PMID: 32348588; PMCID: PMC7267177.

7. Huang C, Wang $\mathrm{Y}, \mathrm{Li}$ X, et al. Clinical features of patients infected with 2019 novel coronavirus in Wuhan, China [published correction appears in Lancet. 2020 Jan 30]. Lancet. 2020; 395(10223):497-506. doi:10.1016/S0140-6736(20)30183-5

8. García LF. Immune Response, Inflammation, and the Clinical Spectrum of COVID-19. Front Immunol. 2020 Jun 16;11:1441. doi: 10.3389/fimmu.2020.01441. PMID: 32612615; PMCID: PMC7308593.

9. Ramdomized Evaluation of COVID-19 Therapy RECOVERY. Low-cost dexamethasone reduces death by up to one third in hospitalised patients with severe respiratory complications of COVID-19. Londres: RECOVERY trial net; 2020 [citado el 11 de noviembre 2020]. Disponible en:https://www.recoverytrial.net/news/low-cost-dexamethasone-reduces-death-by-up-to-one-third-in-hospitalised-patients-with-severe-res- 
piratory-complications-of-covid-19

10. Langford BJ, So M, Raybardhan S, Leung V, Westwood D, MacFadden DR, Soucy JR, Daneman N. Bacterial co-infection and secondary infection in patients with COVID-19: a living rapid review and meta-analysis. Clin Microbiol Infect. 2020 Jul 22:S1198-743X(20)30423-7. doi: 10.1016/j. cmi.2020.07.016. Epub ahead of print. PMID: 32711058.

11. Lansbury L, Lim B, Baskaran V, Lim WS. Co-infections in people with COVID-19: a systematic review and meta-analysis. J Infect. 2020 Aug;81(2):266-275. doi: 10.1016/j.jinf.2020.05.046. Epub 2020 May 27. PMID: 32473235; PMCID: PMC7255350.

12. Luo X, Zhou W, Yan X, Guo T, Wang B, Xia H, Ye L, Xiong J, Jiang Z, Liu $\mathrm{Y}$, Zhang B, Yang W. Prognostic value of $\mathrm{C}$-reactive protein in patients with COVID-19. Clin Infect Dis. 2020 May 23:ciaa641. doi: 10.1093/cid/ ciaa641. Epub ahead of print. PMID: 32445579; PMCID: PMC7314209.

13. Lippi G, Plebani M. Procalcitonin in patients with severe coronavirus disease 2019 (COVID-19): A meta-analysis. Clin Chim Acta. 2020 Jun;505:190191. doi: 10.1016/j.cca.2020.03.004. Epub 2020 Mar 4. PMID: 32145275; PMCID: PMC7094472.

14. Heesom L, Rehnberg L, Nasim-Mohi M, Jackson AIR, Celinski M, Dushianthan A, Cook P, Rivinberg W, Saeed K. Procalcitonin as an antibiotic stewardship tool in COVID-19 patients in the intensive care unit. J Glob Antimicrob Resist. 2020 Sep;22:782-784. doi: 10.1016/j.jgar.2020.07.017. Epub 2020 Jul 25. PMID: 32717489; PMCID: PMC7381395. 